\title{
A visão de professores sobre dificuldades dos alunos na resolução de problemas
}

\section{The teachers' point of view of about students' difficulties in problem solving}

\author{
Marcelo Carlos de Proença ${ }^{1}$
}

\begin{abstract}
Resumo
O objetivo foi analisar as dificuldades encontradas por alunos na visão de professores de Matemática quando se busca realizar o ensino via resolução de problemas. Participaram da pesquisa 29 professores em formação continuada. Coletamos dados antes e após um curso específico de resolução de problemas. Os resultados iniciais mostraram que, na visão dos participantes, as dificuldades dos alunos na resolução dos problemas colocados como ponto de partida estariam relacionadas aos seus conhecimentos sobre conteúdos anteriores e aos seus conhecimentos do conteúdo que será introduzido. Ao final, os resultados mostraram que $72 \%$ dos professores apontaram a necessidade do uso direto do conteúdo nos problemas propostos por eles como o aspecto que dificultaria aos alunos de propor uma estratégia de resolução. Concluímos que as dificuldades dos alunos para resolver problemas abordados como ponto de partida residem na escolha dos problemas, ou seja, no modo como o conteúdo aparece em seus enunciados.
\end{abstract}

Palavras-chave: Ensino de Matemática; Resolução de Problemas; Formação de Professores; Formação Continuada.

\begin{abstract}
The aim was to analyze the difficulties encountered by students in mathematics teachers of vision when it seeks to accomplish the teaching via problem solving. The participants were 29 teachers in continuing education. We collect data before and after a specific course of problem solving. Initial results showed that, in the view of participants, students' difficulties in solving the problems posed as a starting point would be related to their previous knowledge of content and their knowledge of the content that will be introduced. Finally, the results showed that $72 \%$ of teachers indicated the need for direct use of the content in the problems posed by them as the aspect that hinder students to propose a resolution strategy. We conclude that the difficulties of the students to solve problems addressed as a starting point resides in the choice of problems, that is, in the way content appears in their enunciation.
\end{abstract}

Keywords: Mathematics Teaching; Problem Solving; Teacher Education. Continued Education.

\section{Introdução}

A resolução de problemas é indicada nos Parâmetros Curriculares Nacionais - PCN (Brasil, 1997, 1998, 2002) como uma abordagem ao processo de ensino e aprendizagem da

\footnotetext{
${ }^{1}$ Doutor em Ensino de Matemática. Professor do Departamento de Matemática da Universidade Estadual de Maringá, Brasil. E-mail: mcproenca@uem.br
}

Zetetiké, Campinas, SP, v.25, n. 3, set./dez.2017, p.440-456 
DOI: http://dx.doi.org/10.20396/zet.v25i3.8647477

Matemática nos Ensinos Fundamental e Médio. Nos PCN (Brasil, 1997, 1998), aponta-se como foco principal o uso do problema como ponto de partida no ensino e não a definição matemática, buscando favorecer a compreensão de conceitos e procedimentos matemáticos.

Porém, pesquisas mostraram que o trabalho por meio da resolução de problemas no ensino de Matemática tem seguido, equivocadamente, uma abordagem de problemas que serviriam, simplesmente, como uma aplicação de definições, fórmulas, regras e/ou técnicas matemáticas pelos alunos (Redling, 2011; Proença, 2013; Marques, 2013).

O que se observa nessas pesquisas são resultados que evidenciam um ensino que ainda se direciona a um formato do tipo tradicional que consiste em trabalhar conceitos e procedimentos que sejam posteriormente aplicados, sem a devida compreensão, em diferentes situações. Para Miguel (2010), trata-se de uma cultura escolar que ainda se baseia na memorização imitativo-repetitiva de procedimentos algoritmos, situação que quase sempre gera incompreensão dos conteúdos matemáticos por parte dos alunos.

Analisando conhecimentos sobre resolução de problemas de professores que estavam em formação continuada, no Programa de Desenvolvimento Educacional (PDE/PR), Proença (2014) mostrou que dos 26 professores, 7,7\% indicaram realizar um ensino em que o "problema" é colocado após iniciar o conteúdo e que $61,5 \%$ sequer conheciam sobre o assunto, apresentando respostas muito gerais: tem que ser interessante, dinâmico, criativo.

Esses resultados encontrados pelos autores citados acima nos levaram a fazer os seguintes questionamentos: Quais seriam as dificuldades de professores da escola para abordar o problema como ponto de partida no ensino? Como esses professores selecionariam/organizariam situações de Matemática (possíveis problemas) a serem colocadas como ponto de partida e que pudessem levar os alunos a compreender Matemática? Um vez que se tem selecionado determinado problema para se abordado como ponto de partida, quais dificuldades teriam os alunos para resolvê-lo?

A partir desses questionamentos, tivemos interesse em realizar a presente pesquisa, cujo objetivo foi analisar as dificuldades encontradas por alunos na visão de professores de Matemática quando se busca realizar o ensino via resolução de problemas.

\section{A formação de professores e a resolução de problemas}

Autores como Pacheco e Flores (1999) e Imbernón (2011) estudaram a respeito da formação de professores e identificaram quatro fases/momentos de formação que podemos elencar como: a) experiência enquanto aluno da escola, criando-se uma compreensão de trabalho pedagógico comum; b) formação inicial, momento formal de aquisição de conhecimentos da profissão; c) iniciação ao ensino, primeiros anos como professor da escola; d) formação continuada, formação ao longo da carreira docente.

Sobre a formação continuada, Pacheco e Flores (1999) utilizaram a expressão formação contínua e apontaram que envolve as formas de desenvolver o crescimento profissional dos professores. Já Imbernón (2011) a denominou de formação permanente, 
DOI: http://dx.doi.org/10.20396/zet.v25i3.8647477

entendendo-a como o momento de questionar ou legitimar o conhecimento profissional posto em prática, buscando reequilíbrio entre esquemas teóricos e práticos.

Nesse sentido, o aspecto profissional do professor envolve, entre outros assuntos importantes, o desenvolvimento ou (re)estruturação de conhecimento pedagógico, o qual, para Imbernón (2011), corresponde à especificidade da profissão docente. No caso do professor que ensina Matemática, um exemplo desse conhecimento pedagógico é o trabalho na abordagem da resolução de problemas. Assim, seu crescimento profissional implicaria, na fase de formação continuada, no reequilíbrio entre esquemas teóricos sobre a resolução de problemas e práticas pedagógicas coerentes à sua abordagem no ensino.

Desse modo, um dos princípios teóricos da resolução de problemas é o significado da palavra problema. "Para que possamos falar da existência de um problema, a pessoa que está resolvendo essa tarefa precisa encontrar alguma dificuldade que a obrigue a questionarse sobre qual seria o caminho que precisaria seguir para alcançar a meta." (Echeverría, 1998, p. 48, grifo nosso).

Nesse sentido, é diferente dos conhecidos exercícios, uma vez que “[...] um exercício não é só a repetição das operações matemáticas básicas, seja de forma oral ou de forma escrita, mas também pode ser um outro tipo de tarefa na qual o aluno não precisa tomar nenhuma decisão sobre os procedimentos que deve usar para chegar à solução." (Echeverría, 1998, p. 48, grifo nosso).

Sobre esse questionamento sobre qual seria o caminho a ser seguido para alcançar a meta, destaca-se as considerações de Brito (2006). Essa autora analisou teorias e conceitos referentes à resolução de problemas e evidenciou que corresponde a um processo que envolve o uso de conceitos e princípios. Tal processo não implica na utilização de um método óbvio de resolução, mas em uma forma complexa dos processos cognitivos para combinar conceitos e princípios na busca de um caminho de resolução. Para essa autora:

A solução de problemas é, portanto, geradora de um processo através do qual o aprendiz vai combinar, na estrutura cognitiva, os conceitos, princípios, procedimentos, técnicas, habilidades e conhecimentos previamente adquiridos que são necessários para encontrar a solução com uma nova situação que demanda uma reorganização conceitual cognitiva. Trata-se, portanto, de uma re-organização dos elementos já presentes na estrutura cognitiva, combinados com os novos elementos trazidos pela nova situação. (Brito, 2006, p. 19, grifo nosso).

A nova situação refere-se ao problema que, para ser resolvido, necessitaria de uma reorganização conceitual cognitiva. Assim, trata-se do princípio teórico dessa temática que diz respeito ao significado do processo de resolução de problemas, o qual, conforme a literatura revisada por Brito (2006), corresponde a uma sequência de etapas, fases ou estágios.

Mayer (1992) foi um autor que, ao processo de resolução de problemas matemáticos, apontou dois estágios: representação do problema e solução do problema. Cada um envolve dois subestágios e os respectivos conhecimentos necessários ao resolvedor, a saber:

Zetetiké, Campinas, SP, v.25, n. 3, set./dez.2017, p.440-456

ISSN 2176-1744 
DOI: http://dx.doi.org/10.20396/zet.v25i3.8647477

- Representação do problema - envolve os subestágios: Tradução e Integração. Na Tradução, são necessários os conhecimentos linguístico e semântico. Na Integração, o conhecimento esquemático.

- Solução do problema - envolve os subestágios: Planejamento e Monitoramento e o de Execução. No primeiro, é necessário o uso de conhecimento estratégico. $\mathrm{Na}$ Execução, o conhecimento procedimental.

De modo geral, o objetivo de Mayer (1992) foi o de explorar os tipos de conhecimentos necessários à resolução de problemas matemáticos.

Conhecimentos linguístico e semântico: a primeira ação na resolução de um problema é a tradução das informações contidas nesse problema por meio de uma representação mental. $\mathrm{O}$ conhecimento linguístico necessário diz respeito a conhecer a língua portuguesa, ou seja, as palavras. O conhecimento semântico, por sua vez, refere-se em conhecer o significado das palavras, nesse caso, de termos matemáticos e suas relações.

Conhecimento esquemático: por exemplo, reconhecer que um determinado problema é um problema de área, envolvendo a fórmula "área = comprimento x largura", a pessoa tem condições de guiar a atenção e discernir entre dados relevantes e irrelevantes. Segundo Mayer (1992, p. 465), "quando você reconhece que esse problema envolve a fórmula de área, você ativou um esquema para o problema".

Conhecimento estratégico: para resolver um problema, a pessoa precisa ter um conhecimento estratégico para gerar e monitorar um plano de solução. De acordo com Mayer (1992), a partir do momento que a pessoa converteu dados do problema em, por exemplo, uma equação, ela precisaria, agora, criar um plano para resolver essa equação.

Conhecimento procedimental: Após a pessoa ter representado um problema e criado um plano de solução, agora ela deve executar o plano, o que envolve ações como calcular. Por exemplo, saber dividir e multiplicar números na forma decimal corresponde a um conhecimento procedimental de cálculo matemático importante à resolução.

Diante do exposto, Mayer (1992) apontou que no estágio de representação do problema, os conhecimentos linguístico, semântico e esquemático permitem que a pessoa entenda o problema, que ela construa uma representação mental. Desse modo, entende-se que o autor evidencia se tratar de uma etapa que assume papel importante e imprescindível no processo de resolução de problemas. Diante disso, uma representação inadequada de um problema acabaria prejudicando o estágio de solução do problema.

Uma consequência disso seria o fato de não ocorrer uma reorganização coerente de conceitos, princípios e procedimentos com elementos presentes nos problemas, justamente por uma má formação desses conhecimentos, adquiridos previamente, por quem os resolve.

Conforme apontaram Chi \& Glaser (1992, 255, grifo dos autores), “a representação de um problema consiste essencialmente da interpretação ou compreensão do problema por aquele que o soluciona" e é muito importante para facilitar a sua resolução. Assim, para Sternberg (2000, p. 307), "essa etapa é crucial para você descobrir a resposta". 
DOI: http://dx.doi.org/10.20396/zet.v25i3.8647477

Contudo, buscamos evidenciar o que tem caracterizado os dois princípios teóricos da temática da resolução de problemas: a) a definição de problema, enquanto uma situação que demanda o alcance a um objetivo e que não dispõe de um caminho direto de resolução; b) um processo de resolução de problemas, o qual tomamos como referência os estágios de Mayer (1992), que desencadearia a necessidade de uma articulação de conhecimentos prévios (de Matemática) a elementos do problema.

\section{Abordagens da resolução de problemas no ensino de Matemática: sobre, para, via}

Segundo Schroeder e Lester (1989), apesar dos vários esforços, ocorridos na década de 1980, como listas de estratégias para serem ensinadas, no intuito de tornar a resolução de problemas o foco do ensino, não havia uma coerência de qualidade e uma direção clara nessa abordagem. Havia pouca concordância de como essa meta poderia ser alcançada, talvez, pelas diferenças entre as concepções tanto de indivíduos como de grupos do que seria pensar a resolução de problemas como foco da Matemática escolar.

Schroeder \& Lester (1989) apresentaram três abordagens que seriam a maneira de como a resolução de problemas estava sendo ensinada até o momento: ensinar sobre resolução de problemas, ensinar para resolução de problemas e ensinar via resolução de problemas.

- Ensinar sobre resolução de problemas: o ensino era baseado no modelo de Polya, referente a quatro fases: compreensão do problema, elaboração de um plano, execução do plano e retrospecto. "No melhor de suas hipóteses, ensinar sobre resolução de problemas também incluía experiências com, de fato, resolver problemas, mas sempre envolveu muito da discussão explícita de, e ensinar sobre, como problemas são resolvidos." (Schroeder \& Lester, 1989, p. 32).

- Ensinar para resolução de problemas: nessa abordagem, "aos alunos são dados muitos exemplos de conceitos e estruturas matemáticos que eles estão estudando e muitas oportunidades para aplicar a Matemática na resolução de problemas." (Schroeder \& Lester, 1989, p. 32). O professor que ensina para resolver problemas se preocupa com a habilidade do aluno em transferir o que aprendeu para outras situações.

- Ensinar via resolução de problemas: o ensino visa à utilização de problemas como o primeiro passo para aprender Matemática.

O ensino de um tópico matemático começa com uma situação-problema que expressa aspectos-chave desse tópico e técnicas matemáticas são desenvolvidas como respostas razoáveis para problemas razoáveis. Um objetivo de se aprender matemática é o de poder transformar certos problemas não rotineiros em problemas rotineiros. A aprendizagem da matemática, desse modo, pode ser vista como um movimento do concreto (um problema do mundo real que serve como exemplo do conceito ou da técnica matemática) para o abstrato (uma representação simbólica de uma classe de problemas e técnicas para operar com esses símbolos). (Schroeder \& Lester, 1989, p. 33, grifo nosso). 
DOI: http://dx.doi.org/10.20396/zet.v25i3.8647477

De acordo com Schroeder \& Lester (1989), deve-se tomar ciência das limitações que advém dos ensinos "sobre" e "para". No caso do ensino sobre resolução de problemas, podese pensar que essa abordagem é um tópico de Matemática que seria ensinado de forma isolada do conteúdo e das relações matemáticas. No caso do ensino para resolução de problemas, pode-se ter uma limitação maior no sentido de que a "resolução de problemas é vista como uma atividade em que os alunos somente se engajam depois da introdução de um novo conceito ou para seguir uma habilidade de cálculo ou um algoritmo." (Schroeder \& Lester, 1989, p. 34, grifo dos autores).

Diante dessas abordagens apresentadas por Schroeder \& Lester (1989), o ensino via resolução de problemas é a abordagem que está em conformidade ao defendido pelos Parâmetros Curriculares Nacionais de Matemática (Brasil, 1997, 1998), uma vez que ambos indicam o uso do problema como ponto de partida no ensino da Matemática.

Mendes (2009) destaca a importância da resolução de problemas no ensino e na aprendizagem, pois ajudaria os alunos a desenvolverem capacidades como justificar suas respostas e seus processos de resolução e usar fatos conhecidos, propriedades e relações matemáticas para explicar como estão pensando. Para esse autor, conforme os alunos se envolvem nesse processo, alguns chegam a alcançar capacidades mais elevadas de pensamento matemático, relacionadas ao raciocínio dedutivo e indutivo, ao uso do raciocínio espacial, às conjecturas e argumentos matemáticos propostos, à formulação de contraexemplos, o que os ajudam a validar seus próprios pensamentos.

Assim, ao se abordar o ensino via resolução de problemas, entendemos, na perspectiva de Pozo \& Angón (1998), que isso vai depender de como o professor apresenta o problema e da sua funcionalidade na aprendizagem, isto é, uma mesma tarefa pode ser um exercício ou um problema, dependendo de como o professor a apresenta, orienta a sua solução e a avalia.

Nesse sentido, dois critérios dentre os apresentados por esses autores na proposição do problema que consideramos importantes no ensino via resolução de problemas seriam: propor problemas que admitam vários caminhos de resolução e, se possível, várias respostas; evitar que os problemas propostos “[...] apareçam como ilustração, demonstração ou exemplificação de alguns conteúdos previamente apresentados ao aluno." (Pozo \& Angón, 1998, p. 161). Tais critérios indicam que os alunos devem ser levados a compreender que se trata de uma situação problemática onde se tem que pensar e não como algo que se deve seguir uma condição prescritiva (Fi \& Degner, 2012).

\section{Metodologia}

Participaram da presente pesquisa 29 professores que estavam no Programa de Desenvolvimento Educacional - $\mathrm{PDE}^{2}$ do Estado do Paraná, oferecido em uma universidade

\footnotetext{
${ }^{2}$ O PDE é um programa de formação continuada, oferecido a professores que lecionam dos $6^{\circ}$ ao $9^{\circ}$ anos do Ensino Fundamental e no Ensino Médio de escolas públicas do Estado do Paraná. Cada turma de professores participa por um período de dois anos. No primeiro ano, além da produção didático-pedagógica desenvolvida Zetetiké, Campinas, SP, v.25, n. 3, set./dez.2017, p.440-456

ISSN 2176-1744
} 
DOI: http://dx.doi.org/10.20396/zet.v25i3.8647477

estadual pública do interior (turma do biênio 2014-2015). O contexto de investigação correspondeu a um curso específico sobre resolução de problemas, de 16 horas, ministrado pelo autor deste estudo, ao final do segundo semestre de 2014.

Nesse curso específico, o objetivo foi o de favorecer aos professores uma formação nos seguintes temas: a) o significado do termo problema; b) o significado do processo de resolução de problemas; c) as abordagens de resolução de problemas no ensino de Matemática; d) uma condução de aulas para abordar o ensino via resolução de problemas.

Nas primeiras oito horas do curso, os significados de problema e do processo de resolução de problemas foram abordados ao longo da resolução de oito problemas que apresentamos aos professores e que foram solicitados a resolverem, em grupo de quatro pessoas, bem como a apresentação, em lousa, das estratégias utilizadas. A cada situação de Matemática resolvida, discutimos se era difícil para eles e se seria difícil aos alunos. Discutimos também os tipos de estratégias que os professores conseguiram apresentar e as que o autor (professor do curso) apresentou para dar-lhes condições de compor um quadro de estratégias a serem previstas quando fossem ensinar por meio da resolução de problemas.

Após a resolução de cinco problemas, passamos a apresentar slides com informações teóricas em que se discutiu o significado do que seria um problema, bem como a diferença entre problema e exercício. Ao final da resolução dos oito problemas, apresentamos, por meio de slides, o significado do processo de resolução de problemas com base nas ideias de Mayer (1992) sobre os dois estágios de resolução de problemas e os respectivos conhecimentos. Fizemos, assim, uma discussão sobre as dificuldades dos professores, bem como as possíveis dificuldades dos alunos, na resolução dos problemas em termos de conhecimentos linguístico, semânticos, esquemático, estratégico e procedimental, a qual se estendeu para as quatro horas seguintes do curso.

No início das quatro horas finais da formação oferecida, retomamos um questionário que foi aplicado logo nos primeiros momentos do curso para coletar dados do nosso estudo ( $1^{\text {a }}$ fase, descrita mais adiante). A partir das repostas dadas, fizemos uma discussão preliminar para identificar se os problemas escolhidos por eles para serem abordados como ponto de partida, conforme indicam os PCN (Brasil, 1998), permitiam aos alunos utilizar diversas estratégias de resolução.

Essa discussão foi embasada nas abordagens da resolução de problemas, segundo a perspectiva de Schroeder \& Lester (1989) (ensinos sobre, para e via) e foram apresentadas por meio de slides. Buscamos situar os professores nas escolhas dos problemas escolhidos, elucidando se estavam realizando um ensino em que o problema estaria servindo como aplicação de conteúdos (ensinar para resolução de problemas) ou como um caminho para se aprender novos conceitos/conteúdos/assuntos de Matemática (ensinar via resolução de problemas).

junto a um orientador e de outros cursos mais gerais, os professores participam de cursos específicos da área de Matemática, sendo um deles o nosso contexto de pesquisa.

Zetetiké, Campinas, SP, v.25, n. 3, set./dez.2017, p.440-456 
DOI: http://dx.doi.org/10.20396/zet.v25i3.8647477

Por fim, a parte final dos slides continha explicações sobre a condução de aulas no ensino via resolução de problemas em que discutimos as possibilidades e dificuldades no ensino e na aprendizagem de conteúdos de Matemática, baseada na seguinte sequência: introdução de um conteúdo/conceito por meio de um problema, auxílio aos alunos (em grupos) quando da tentativa de resolução, discussão com a classe das estratégias dos grupos, articulação das estratégias ao conteúdo/conceito.

$\mathrm{Na}$ introdução do problema (possível problema), destacamos que era justamente o ato de iniciar um conceito/assunto/conteúdo por meio de um problema e que era necessário o professor realizar um levantamento das possíveis estratégias. No auxílio aos alunos, os professores devem (deveriam) atuar como incentivadores e mediadores das resoluções dos alunos, os quais seriam separados em grupos, permitindo a troca de ideias sobre a compreensão que apresentariam do problema e das estratégias a serem utilizadas. Destacamos aos professores que isso ajudaria a revelar as dificuldades dos alunos em termos dos conhecimentos apontados por Mayer (1992) necessários à resolução de problemas. Na discussão com a classe, enfatizamos que o professor deve incentivar os alunos a exporem suas estratégias em lousa. Por fim, na articulação das estratégias, o ponto principal foi a necessidade de se incentivar os professores a buscarem articular as estratégias dos grupos ao novo conceito/assunto/conteúdo que ser quer ensinar.

Após essa discussão, a parte final do curso foi destinada para que os professores, a partir de livros didáticos que utilizavam em suas aulas, escolhessem situações de Matemática que poderiam ser utilizadas como ponto de partida, apontando possíveis estratégias de resolução. Também tiveram que escolher aquelas que, se utilizadas como ponto de partida, não permitiriam a abordagem de um novo conceito/assunto/conteúdo de modo que os alunos somente a resolveriam se conhecessem os novos conceitos/assuntos/conteúdos. Essa segunda escolha correspondeu à nossa $2^{\mathrm{a}}$ fase de coleta de dados.

Diante desse contexto, realizamos uma pesquisa com o objetivo de analisar as dificuldades encontradas por alunos, na visão dos participantes do estudo, quando se busca realizar o ensino via resolução de problemas. Trata-se, assim, de uma pesquisa qualitativa, uma vez que se "[...] parte do fundamento de que há uma relação dinâmica entre o mundo real e o sujeito, uma interdependência viva entre o sujeito e o objeto, um vínculo indissociável entre o mundo objetivo e a subjetividade do sujeito." (Chizzotti, 2001, p. 79).

Tendo em vista o foco nessa visão de mundo desses professores - a subjetividade dos participantes -, desenvolvemos uma pesquisa exploratória que consistiu em esclarecer tais dificuldades, buscando dar uma visão geral para estudos futuros sobre o ensino via resolução de problemas, e uma pesquisa descritiva, pois o foco foi a descrição das características dessas dificuldades dos alunos, quando o problema é adotado como ponto de partida para introduzir um conteúdo (Gil, 2012).

Para coletar dados referentes à nossa investigação, realizamos duas fases:

$\mathbf{1}^{\mathrm{a}}$ fase: Antes de iniciar o curso sobre resolução de problemas, aplicamos um questionário, composto de duas partes: 
DOI: http://dx.doi.org/10.20396/zet.v25i3.8647477

- Na primeira parte, havia perguntas para saber a formação acadêmica, o tempo em que lecionaram como professor de Matemática, o gênero, se já tinham ensinado Matemática na perspectiva da resolução de problemas e como a abordagem em sala de aula. A questão, cujos dados analisamos neste artigo, solicitava, primeiro, a indicação de um conteúdo de Matemática. Em seguida, solicitava a descrição de uma situação de Matemática (possível problema), a qual o participante utiliza (utilizaria) para trabalhar esse conteúdo por meio da resolução de problemas em sala de aula. Quando faltou uma semana para iniciar o curso, solicitamos aos participantes que fizessem de antemão a escolha dos conteúdos e das respectivas situações de Matemática. Procuramos dar tempo para decidirem sobre suas escolhas e porque, possivelmente, seriam derivadas de suas experiências e conhecimentos no uso de situações de Matemática em suas aulas quando o assunto é o trabalho baseado na resolução de problemas.

- Na segunda parte, solicitamos o seguinte: Adotando essa situação de Matemática como ponto de partida no ensino desse conteúdo (ou seja, antes de abordar o conteúdo em si), responda: Essa situação de Matemática pode ser resolvida por meio do uso de várias estratégias de resolução, ou seja, que os alunos tenham essa oportunidade a partir de seus conhecimentos prévios? Explique.

Assim, no primeiro dia do referido curso, receberam, inicialmente, apenas a primeira parte do questionário, respondendo-o individualmente. Após isso, entregamos a segunda parte. Isso ocorreu porque como já prevíamos que alguns professores trariam mais de um conteúdo e, assim, mais de uma situação de Matemática, episódio que aconteceu, a entrega simultânea das duas partes do questionário permitir-lhes-ia conhecer o teor das questões e, possivelmente, interferir na escolha do conteúdo e da situação de Matemática, bem como na resposta da última questão. Conforme já descrevemos anteriormente, as respostas dadas no questionário foram retomadas ao final do curso específico, promovendo a discussão/reflexão coletiva com os professores sobre os temas abordados a respeito da resolução de problemas.

$2^{\mathbf{a}}$ fase: Após o curso de resolução de problemas, entregamos uma folha aos professores para que respondessem ao seguinte: Tendo em vista a abordagem do problema como ponto de partida, indique um conteúdo e dê um exemplo de uma situação de Matemática que seria inadequada para permitir que os alunos utilizassem diferentes estratégias de resolução. Explique sua resposta.

Para analisar os dados coletados, elaboramos categorias, baseadas nas seguintes regras: “a) o conjunto de categorias deve ser derivado de um único princípio de classificação; b) o conjunto de categorias deve ser exaustivo [incluir todas as respostas]; c) as categorias do conjunto devem ser mutuamente exclusivas [cada resposta em uma única categoria]." (Selltiz et al., 1967, p. 441 apud Gil, 2012, p. 157-158).

Diante disso, as denominações das categorias propostas em nossa análise foram definidas após a classificação e delimitação dos dados coletados. Pata tal, o princípio de classificação das categorias foi relacionado ao conhecimento por parte dos alunos do conteúdo/conceito envolvido, levando-se em consideração a visão dos professores Zetetiké, Campinas, SP, v.25, n. 3, set./dez.2017, p.440-456 
DOI: http://dx.doi.org/10.20396/zet.v25i3.8647477

participantes da pesquisa sobre as dificuldades que esses alunos teriam para apresentar/propor suas estratégias de resolução.

Assim, as duas categorias de análise das dificuldades apontadas no questionário foram as seguintes: (a) $\mathbf{O}$ aluno deve (deveria) ter conhecimentos sobre conteúdos anteriores envolveu explicações que apontavam que os alunos deveriam ter aprendido conhecimentos de conteúdos/assuntos anteriores ao conteúdo específico de Matemática que indicaram e que tais conhecimentos deveriam ser utilizados na situação de Matemática; (b) $\mathbf{O}$ aluno deveria ter o conhecimento desse conteúdo - envolveu explicações que apontavam a necessidade do conhecimento do conteúdo sugerido na situação de Matemática apresentada, ou seja, do uso direto do conteúdo (fórmula, regra, conceito) na resolução.

Por fim, para analisar os dados da atividade aplicada ao final do curso, elencamos três categorias, a saber: (a) Necessidade do uso direto do conceito/fórmula de Matemática corresponde às explicações direcionadas ao fato de que o conteúdo envolvido era a única forma de resolução da atividade de Matemática; (b) Necessidade de o aluno responder a vários itens - correspondeu a explicações que indicaram necessidade de se responder a uma sequência de perguntas do tipo a), b) e c), solicitadas na atividade de Matemática; (c) Deixou em branco - respostas em branco.

\section{Análise e discussão dos dados}

Os professores que participaram da pesquisa se caracterizavam quanto ao gênero da seguinte forma: a maioria, $96,6 \%$, era do gênero feminino e apenas $3,4 \%$, masculino.

A respeito das atividades que os professores utilizam (ou utilizariam) para introduzir os conteúdos indicados na perspectiva da resolução de problemas em sala de aula, questionamos: Essa situação de Matemática pode ser resolvida por meio do uso de várias estratégias de resolução, ou seja, que os alunos tenham essa oportunidade a partir de seus conhecimentos prévios? Explique.

Identificamos que 17,2\% dos professores participantes responderam que não, indicando dificuldades para que a atividade proposta pudesse ser resolvida pelos alunos por várias estratégias ou pelo menos mais de uma estratégia. A Tabela 1, abaixo, mostra que, dos $17,2 \%, 20 \%$ apresentaram dificuldades que se enquadraram em uma categoria de análise e a maioria deles, $80 \%$, na outra.

Tabela 1 - Categorias das dificuldades elencadas pelos professores.

\begin{tabular}{lcc}
\hline \multicolumn{1}{c}{ Dificuldades } & $\%$ & Conteúdos \\
\hline $\begin{array}{l}\text { O aluno deve (deveria) ter conhecimentos sobre } \\
\text { conteúdos anteriores }\end{array}$ & 20 & Frações \\
O aluno deveria ter o conhecimento desse conteúdo & 80 & $\begin{array}{c}\text { Cálculo das possibilidades, } \\
\text { Função do } 1^{\circ} \text { grau, } \\
\text { Porcentagem, Aplicação de } \\
\text { logaritmo }\end{array}$ \\
\hline
\end{tabular}


Fonte: $\mathrm{O}$ autor.

DOI: http://dx.doi.org/10.20396/zet.v25i3.8647477

Verifica-se que a primeira categoria de dificuldades envolve somente o conteúdo Frações. A atividade de Matemática proposta foi a seguinte: "Uma prova de concurso era composta por questões de Matemática, Português, Inglês e pela elaboração de uma redação. Flávio começou a resolver essa prova às $13 \mathrm{~h}$ e terminou às $17 \mathrm{~h}$. Do tempo de duração da prova, 7/20 Flávio resolveu as questões de Matemática, em 1/5, as questões de Português, em 3/20, as de Inglês e no restante do tempo elaborou a redação. Que fração do tempo da prova Flávio demorou para elaborar a redação?"

A explicação dada se remeteu à seguinte dificuldade que os alunos teriam para utilizar diferentes estratégias de resolução:

"Creio que seja preciso um bom entendimento sobre as frações, suas partes e o todo para que possam criar possibilidades de resolução ou tentativas. "

Tal atividade de Matemática poderia ser ponto de partida para introduzir o conteúdo de soma de frações, ou seja, à aprendizagem do algoritmo da adição. Assim, a(s) estratégia(s) que poderia(m) ser utilizada(s) se basearia(m) justamente no que revela essa explicação: a necessidade de um conhecimento prévio pelo aluno sobre a relação parte-todo do ponto de vista conceitual, o que envolveria o conhecimento prévio de equivalência de frações para transformar um quinto em quatro vinte avos e, assim, somar os numeradores e verificar o que falta para chegar ao vinte (inteiro), tendo possibilidade de encontrar a resposta. Isso também poderia ser feito por meio da construção de retângulos de cada fração.

Verifica-se que uma resolução seria montar e resolver uma equação, utilizando-se de cálculo do mínimo múltiplo comum. No entanto, uma vez que na explicação acima se visualizou a possibilidade de novas estratégias, infere-se a importância de se ter desenvolvido conhecimento semântico (Mayer, 1992) sobre a relação parte-todo de cada uma das frações que aparecem no enunciado da atividade de Matemática proposta.

$\mathrm{Na}$ segunda categoria, exemplificamos as dificuldades elencadas pelos participantes por meio do conteúdo Porcentagem. Segue abaixo a atividade indicada: "O aluguel de uma casa, que era de $\mathrm{R} \$ 400,00$ teve um aumento de $30 \%$. O novo valor do aluguel passou a ser de:".

A explicação dada foi referente à seguinte dificuldade que os alunos teriam para utilizar diferentes estratégias de resolução:

"Provavelmente esse aluno não tem os conhecimentos necessários se tratando do alunado do $6^{\circ}$ ano."

Apesar de nessa explicação acima não se ter indicado especificamente qual o conhecimento necessário, inferimos se tratar do conhecimento do termo "30\%" e de como 
DOI: http://dx.doi.org/10.20396/zet.v25i3.8647477

operá-lo para encontrar a resposta. Conforme se indica nos PCN (Brasil, 1997), uma abordagem desse conteúdo ocorre nos anos escolares anteriores ao mencionado pelo participante no âmbito do cálculo simples, do reconhecimento do conceito de porcentagem. No entanto, nesse documento, é indicada uma abordagem formal desse conteúdo a partir do sexto ano do Ensino Fundamental, estando coerente à explicação dada pelo participante.

Na perspectiva de Mayer (1992), o termo "30\%” corresponderia a um conhecimento semântico, uma vez que envolve o significado de um termo matemático e, assim, o estabelecimento de uma relação matemática como, por exemplo, a sua representação na forma decimal ou fracionária e de como operar matematicamente com essas representações. Entende-se que o uso da simbologia "\%" não permite compreender por si só seu significado. O aluno que nunca o tenho visto ou que não foi esclarecido sobre tal, não conseguirá realizar uma representação adequada do problema que o permita resolvê-lo, justamente pela falta desse conhecimento semântico.

$\mathrm{Na}$ visão de Brito (2006), infere-se que, ao tentar resolver problemas com essa característica por meio da combinação dos conhecimentos adquiridos previamente à nova situação, os alunos vão se deparar a um novo elemento - o significado de \% - que nesse caso não vai permitir a reorganização conceitual cognitiva via essa tentativa de combinação.

Ao final do curso de resolução de problemas, os professores responderam ao seguinte: Tendo em vista a abordagem do problema como ponto de partida, indique um conteúdo e dê um exemplo de uma situação de Matemática que seria inadequada para permitir que os alunos utilizassem diferentes estratégias de resolução. Explique sua resposta.

Nesse momento, apesar de todos os 29 professores estarem presentes, apenas 25 deles devolveram ao pesquisador a folha que continha essa atividade. Assim, a análise dos dados envolveu esse número de participantes $(\mathrm{n}=25)$. A Tabela 2 mostra as três categorias de explicações dadas pelos professores.

Tabela 2 - Categorias, envolvendo explicações às atividades inadequadas.

\begin{tabular}{lcc}
\hline \multicolumn{1}{c}{ Explicação } & \% (n=25) & Conteúdos \\
\hline $\begin{array}{l}\text { Necessidade do uso direto do } \\
\text { conceito/fórmula de Matemática }\end{array}$ & 72 & $\begin{array}{c}\text { Matrizes, Juros Composto, Progressão } \\
\text { Geométrica, Função Afim, Expressões } \\
\text { algébricas, Porcentagem, Adição com } \\
\text { Naturais, Fração, Teorema de Pitágoras, } \\
\text { Subtração com decimais, Medidas de } \\
\text { tempo, Logaritmo, Medidas de ângulo, } \\
\text { Grandezas e Medidas }\end{array}$ \\
$\begin{array}{l}\text { Necessidade de o aluno responder a vários } \\
\text { itens }\end{array}$ & 16 & $\begin{array}{c}\text { Operações com Números Naturais, } \\
\text { Função do } 1^{\circ} \text { grau, Porcentagem }\end{array}$ \\
Deixou em branco & 12 & \\
Total & 100 & \\
\hline
\end{tabular}

Fonte: $\mathrm{O}$ autor. 
$\mathrm{Na}$ primeira categoria, Necessidade do uso direto do conceito/fórmula de Matemática, ilustramos por meio da seguinte atividade de Matemática que envolveu Juros Compostos. "Um capital de $\mathrm{R} \$ 640,00$ foi aplicado durante três meses a uma taxa de juros composto de $2 \%$ a.m. Quantos reais de juro rendeu essa aplicação?”

Assim, a explicação abaixo ilustra o porquê da atividade ser inadequada para que os alunos tenham condições de obter estratégias de resolução.

"Essa atividade seria inadequada para permitir que os alunos utilizassem diferentes estratégias de resolução, pois ele não tem conhecimento necessário para realizar o cálculo de juros composto."

Essa explicação acima evidencia uma dificuldade relativa à necessidade do conhecimento semântico de juro composto. Observa-se que a explicação do participante evidencia que os alunos não conseguiriam resolver a atividade de Matemática por meio de estratégias diferentes justamente porque a única estratégia seria via uso direto do conteúdo/conceito que se quer introduzir.

Nesse sentido, se essa atividade fosse selecionada para ser abordada como ponto de partida (problema) na introdução do conteúdo Juros Compostos, então a possibilidade de resolução por parte dos alunos só poderia ocorrer se, no ensino, primeiro fosse apresentado sua definição/conceito para posterior aplicação. Assim, ocorreria uma forma equivocada de se abordar um problema em sala de aula, configurando-se na abordagem de ensinar para resolução de problemas.

Ao contrário disso, buscando favorecer o ensino via resolução de problemas a futuras professoras de pedagogia, Proença (2015) trabalhou problemas de assuntos específicos do conteúdo de fração que pudessem ser introduzidos sem a recorrência direta a algoritmos ou simbologias específicos, tendo como foco a articulação de estratégias aos assuntos abordados. Desse modo, mostrou-se que $56 \%$ das futuras pedagogas apresentaram compreensão da necessidade de se buscar tal articulação.

A respeito da segunda categoria de explicações, Necessidade de o aluno responder a vários itens, a atividade seguinte, envolvendo Função de $1^{\circ}$ Grau, a ilustra: "Numa fábrica de bichos de pelúcia, o custo para produção de um determinado modelo é de $\mathrm{R} \$ 12,50$ por unidade, mais um custo inicial de R \$ 370,00. Qual é o custo de produção de 100, 120, 300 unidades do produto?".

A explicação dada pelo participante mostrou que essa atividade seria inadequada para que os alunos pudessem propor suas estratégias de resolução se fosse apresentada com mais de uma questão, solicitando mais de uma resposta.

"Seria inadequado lançar o mesmo problema e pedir mais de uma resposta, como por exemplo: a) Qual é o custo de produção de 100, 120, 300 unidades do produto? b) Faça uma tabela desses dados. c) Construa o gráfico desta função." 
Do ponto de vista do significado do termo problema, essa explicação é coerente com a literatura estudada no curso de resolução de problemas sobre tal significado, pois resolver um problema corresponde, segundo Echeverría (1998), a encontrar um caminho que ajude a alcançar a meta, a resposta. Assim, a tentativa de resolução deveria ter como foco a busca de uma resposta ou respostas a uma única pergunta.

Entende-se que atividades com várias perguntas poderiam se enquadrar na função de aulas baseadas em exercícios, envolvendo aplicação direta de conhecimentos que estão sendo aprendidos, uma vez que para responder à questão seguinte os alunos precisariam acertar as respostas anteriores.

\section{Conclusão}

No contexto de um curso específico de resolução de problemas em um programa de formação continuada, realizamos um estudo que teve com objetivo o de analisar as dificuldades encontradas por alunos na visão de professores de Matemática quando se busca realizar o ensino via resolução de problemas.

A análise dos conteúdos fração e porcentagem evidenciou as dificuldades elencadas pelos $17,2 \%$ dos professores $(\mathrm{n}=29)$, direcionadas à necessidade de o aluno da escola básica ter desenvolvido conhecimentos prévios relacionados ao conteúdo/conceito que se quer ensinar. Evidenciou, sobretudo, como no exemplo do conteúdo porcentagem, que se no enunciado da situação de Matemática a ser abordada como ponto de partida há uma simbologia matemática (conhecimento semântico) ainda formalmente desconhecida pelos alunos, então a introdução do respectivo conteúdo/conceito não vai se enquadrar na abordagem do ensino via resolução de problemas.

Após o curso de resolução de problemas, a análise das situações de Matemática e explicações dadas pelos professores como inadequadas à proposição de estratégias de resolução por parte dos alunos mostrou que $72 \%(n=25)$ perceberam que quando uma situação (inserida como problema) é colocada como ponto de partida, a dificuldade para se configurar na abordagem de ensinar via resolução de problemas decorre do fato de sua resolução exigir o uso direto do conteúdo (definição, conceito e/ou fórmula), conforme análise do caso do conteúdo Juros Compostos.

Contudo, a visão dos professores de Matemática mostra que, quando se adota o problema como ponto de partida no ensino, as dificuldades dos alunos para conseguirem resolvê-lo por meio de suas estratégias residem na escolha dos problemas que serão utilizados para introduzir os conteúdos. Essas escolhas implicam justamente no modo como o conteúdo/assunto/conceito aparece no enunciado dos problemas. Além disso, essa visão revela que, quando se escolhe determinado problema a ser adotado como ponto de partida, os professores precisam estar conscientes de que um novo conteúdo/assunto/conceito deve ser atingido e que, para tal, deve-se valorizar os conhecimentos prévios dos alunos. 
DOI: http://dx.doi.org/10.20396/zet.v25i3.8647477

Diante disso, segundo os dados analisados, gostaríamos de destacar que, tanto na primeira fase como na segunda fase, as situações de Matemática (possíveis problemas) escolhidas e apresentadas pelos professores tiveram como natureza o fato de serem contextualizadas e não como uma situação estritamente matemática. Entendemos que o uso de situações contextualizadas deveria tomar maior espaço ou mesmo ser o princípio no/do ensino via resolução de problemas, pois ajudaria a favorecer aos alunos uma compreensão em níveis de abstração mais consistentes dos conteúdos matemáticos do que simplesmente ensiná-los para que sejam aplicados nesses tipos de situações. Acreditamos que o professor da escola tem grande interesse no uso de situações contextualizadas e que reconhecem sua importância no ensino, conforme nosso entendimento.

Como implicações deste estudo, uma das grandes dificuldades que levaria o professor da escola a não conseguir trabalhar na abordagem do ensino via resolução de problemas esteja nas escolhas inadequadas das situações de Matemática (possíveis problemas) que possam introduzir os conteúdos. Possivelmente, em tal escolha o professor acabe se deparando com a necessidade do uso direto de definições, conceitos, fórmulas e regras, direcionando, consequentemente, seu ensino à abordagem do ensinar para resolução de problemas. Nesse sentido, seria importante realizar pesquisas ligadas diretamente à sala de aula sobre como os professores fazem a seleção/escolha de situações de Matemática quando procuram abordá-las na perspectiva do ensino via resolução de problemas.

Por fim, gostaríamos de apontar algumas considerações sobre o tipo de investigação que fizemos. Apontamos como ponto positivo o fato de se ter aproveitado o curso específico para buscar analisar a compreensão dos professores sobre a resolução de problemas no ensino de Matemática. Trata-se de um ponto positivo porque esses professores estavam em um programa de formação continuada que exige plena participação e, assim, devem mostrar interesse no que estava sendo proposto, fato esse que podemos confirmar, pois foi verificada uma participação ativa da maioria dos professores. A não confirmação da totalidade deles foi verificada ao final do curso, uma vez que quatro professores não responderam à atividade final e um percentual de $12 \%$ ( $n=25$; três professores) deixaram em branco. Diante disso, um dos limites para realizar investigações em termos de formação continuada seja o de conseguir contar com a participação efetiva de todos os professores, que se dispõem a vivenciar cursos, na realização de todas as atividades propostas.

\section{Referências}

Brasil. (2002). Secretaria de educação média e tecnológica. Parâmetros Curriculares Nacionais: ensino médio. Brasília: MEC/SEMTEC.

(1998). Secretaria de ensino fundamental. Parâmetros Curriculares Nacionais: matemática, $3^{\circ}$ e $4^{\circ}$ Ciclos. Brasília: SEF/MEC.

(1997). Secretaria de Ensino Fundamental. Parâmetros Curriculares Nacionais: matemática, $1^{\circ}$ e $2^{\circ}$ Ciclos. Brasília: SEF/MEC. 
DOI: http://dx.doi.org/10.20396/zet.v25i3.8647477

Brito, M. R. F. (2006). Alguns aspectos teóricos e conceituais da solução de problemas matemáticos. In: M. R. F. Brito (Org.). Solução de problemas e a matemática escolar (pp. 13-53). Campinas: Alínea.

Chi, M. T. H., \& Glaser, R. (1992). A capacidade para a solução de problemas. In: R. Sternberg (Org.). As capacidades intelectuais humanas: uma abordagem em processamento de informações (pp. 249-275). Trad. Dayse Batista. Porto Alegre: Artes Médicas.

Chizzotti, A. (2001). Pesquisa em ciências humanas e sociais. 5. ed. São Paulo: Cortez.

Echeverría, M. P. P. (1998). A solução de problemas em matemática. In: P. I. Pozo (Org.). A solução de problemas: aprender a resolver, resolver para aprender, (pp. 43-65). Porto Alegre: ArtMed.

Fi, C. D., \& Degner, K. M. (2012). Teaching through problem solving. Mathematics Teacher, 105(6), 455-459.

Gil, A. C. (2012). Métodos e técnicas de pesquisa social. 6. ed. São Paulo: Atlas.

Imbernón, F. (2011). Formação docente e profissional: formar-se para a mudança e a incerteza. Trad. Silvana Cobucci Leite. $9^{a}$ ed. São Paulo: Cortez.

Marques, W. C. (2013). Narrativas sobre a prática de ensino de matemática de professores dos anos iniciais do ensino fundamental. (Dissertação de Mestrado em Educação Matemática). Rio Claro: Universidade Estadual Paulista.

Mayer, R. E. (1992). Thinking, problem solving, cognition. $2^{\mathrm{a}}$ ed. New York: WH Freeman and Company.

Mendes, I. A. (2009). Matemática e investigação em sala de aula: tecendo redes cognitivas na aprendizagem. São Paulo: Livraria da Física.

Miguel, J. C. (2010). Da resolução de problemas à formação de conceitos matemáticos: implicações teóricas e metodológicas. Anais do $15^{\circ}$ Encontro Nacional de Didática e Prática de Ensino. Belo Horizonte: XV ENDIPE.

Pacheco, J. A., \& Flores, M. A. (1999). Formação e avaliação de professores. Porto: Porto Editora.

Polya, G. (1994). A arte de resolver problemas: um novo enfoque do método matemático. Trad. Heitor Lisboa de Araújo. Rio de Janeiro: Interciência.

Pozo, J. I. \& Angón, Y. M. (1998). A solução de problemas como conteúdo procedimental da educação básica. In: J. I. Pozo (Org.). A solução de problemas: aprender a resolver, resolver para aprender (pp. 139-165). Porto Alegre: ArtMed.

Proença, M. C. (2015). O ensino de frações via resolução de problemas na formação de futuras professoras de pedagogia. Bolema, 29(52), 729-755.

. (2014). O ensino por meio da resolução de problemas: conhecimentos e perspectivas de professores de matemática do PDE. Anais do $14^{\circ}$ Encontro Paranaense de Educação Matemática. Campo Mourão-PR: EPREM.

. (2013). Resolução de problemas e formação de professores que ensinam matemática: análise dos trabalhos do encontro nacional de educação matemática. Anais do $11^{\circ}$ Encontro Nacional de Educação Matemática. Curitiba: SBEM. 
DOI: http://dx.doi.org/10.20396/zet.v25i3.8647477

Redling, J. P. (2011). A metodologia de resolução de problemas: concepções e práticas pedagógicas de professores do ensino fundamental. (Dissertação de Mestrado em Ensino de Ciências e Matemática). Bauru: Universidade Estadual Paulista.

Schroeder, T. L., \& Lester, F. K. (1989). Developing understanding in mathematics via problem solving. In P. R. Trafton \& A. P. Shulte (Eds.). New directions for elementary school mathematics (pp. 31-42). Reston: NCTM.

Sternberg, R. (2000). Psicologia cognitiva. Trad. Maria Regina Borges Osório. Porto Alegre: ArtMed. 